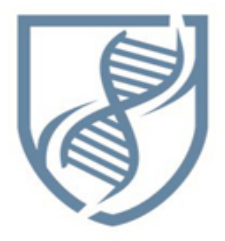

Journal of Bioscience and Applied Research

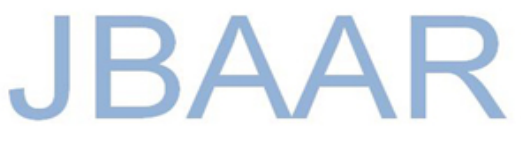

WWW.JBAAR.ORG

\title{
Microbiological and molecular studies on Salmonella spp. isolated from broilers in Kafr El-Sheikh governorate, Egypt
}

\author{
Mohamed T. Shaaban ${ }^{1}$, Hegazy, A.M ${ }^{2}$,Sami I.Menisy ${ }^{3}$ \\ 1,3-Botany Department, Faculty of Science, Menoufia University, Egypt \\ 2- Animal Health Research Institute , Kafr El -Sheikh Regional Lab ,Egypt \\ Corresponding author e-mail. dr.sami_lab@yahoo.com
}

\begin{abstract}
Prevalence of Salmonella pathogen in poultry in Kafr El Sheikh governorate, Egypt were analyzed in 100 pooled samples from poultry (liver, spleen, cloacal swab, gall bladder ), using culture and PCR based methods. The results showed that $S$. enteric was detected in 10 samples (10\%), S. enterica serovar Enteritidis, S. enterica serovars Typhimurium and non-typable serovars were detected in $4(40 \%), 2(20 \%)$ and $4(40 \%)$ respectively . All isolates were multi-drug resistant .Also, all isolates had drug resistant genes except for only one isolate was $S$. enterica serovar Enteritidis . No integrons were detected.
\end{abstract}

Keywords. Poultry, Salmonella spp., MDR (multidrug resistance ),PCR, resistance gene.

\section{Introduction}

The genus Salmonella is phylogenetically clustered in the family of Enterobacteriaceae (Bennasar et al., 2000). Most Salmonella are motile, with the exception of the poultryspecific serotypes of S.gallinarium and S. pullorum (Grimont et al., 2000). Salmonella spp are typically found in soil, water, food, and the gastro-intestinal tract of humans and other animals (Anderson and Ziprin, 2001). Salmonella is Gram-negative, intracellular, straight rod shaped, facultative, non-spore forming, and generally motile with peritrichous flagella (Molbak et al., 2006). The bacterium has a width of 0.7 to $1.5 \mu \mathrm{m}$ and a length of 2.0 to $5.0 \mu \mathrm{m}$ (Holt et al., 1994).
Most Salmonella ferment glucose and produce hydrogen sulfide gas with or without acid; however, S. typhi are incapable of producing gas from fermentation of glucose. Furthermore, most Salmonella are unable to attack lactose and sucrose. Salmonella are non-tolerant to oxidase and can convert nitrate to nitrite. In addition, lysine and ornithine are decarboxylated by Salmonella. Salmonella nomenclature is credited to early pioneers such as White, Borman,Kauffmann, Edwards, and Le Minor (Hanes, 2003).

Over the years, the Salmonella nomenclature system has been revised several times (Euzeby, 1999). Started by White and followed by Kauffmann, a one serotype-one species concept, known as the Kauffmann and White system, was created based on the somatic " O ", flagella " $\mathrm{H} "$ and surface envelope (Vi) antigens (Brenner et al., 2000; Grimont et al., 2000). Not long after its creation, the one serotype-one species concept was discontinued, since most serotypes were closely related (Andrews and Baumler, 2005).

There are several methods of pathogen typing systems. They are divided into two categories: phenotypic (conventional, traditional) and genotypic (molecular, PCRbased). Phenotypic systems include serotyping, phage typing, antibiotic resistance (R-type), biotyping, antibiogram, and bacteriocin (Cooke et al., 2007).

Antimicrobial agents have been widely used in poultry to treat infections caused by a variety of bacterial pathogens. However, this widespread use of large quantities of antimicrobials in poultry in some countries, including Egypt, often without professional consultation or supervision, is problematic. Furthermore, the use of 
antibiotics as growth promoters in poultry feeds has been permitted worldwide for the last 60 years (Aarestrup, 2005). However, concerns about development of antimicrobial resistance and zoonotic transfer ofantibiotic resistance genes led to withdrawal of approval for antibiotics as growth promoters in European poultry feeds (Castanon, 2007).Antibiotics have long been the first line 2.2.3-Molecular methods of defense to prevent bacterial infection, but have lost their 2.2.3.1-Bacterial DNA preparation for, polymerase chain potency as bacteria have grown increasingly resistant to reaction :

treatment (Singer and Hofacre, 2006). Bacterial An overnight bacterial culture $(200 \mu \mathrm{L})$ was mixed with antimicrobial resistance is a serious emerging public health $800 \mu \mathrm{L}$ of distilled water and boiled for 10 min. The concern because of the compromised efficacy of resulting solution was centrifuged and the supernatant used antimicrobial agents used in the treatment of infectious as the DNA template. Amplification reactions were carried diseases (Martinez and Baquero,2002). Intense animal and out with $10 \mu \mathrm{L}$ of boiled bacterial suspensions, $250 \mathrm{mM}$ bird farming, in which antibiotics are routinely used as deoxynucleoside triphosphate, $2.5 \mathrm{mM} \mathrm{MgCl} 2,50 \mathrm{pmol}_{2}$ of growth promoting and therapeutic agents, could be a source for development of antimicrobial resistance (Singer and Hofacre, 2006). Multidrug-resistant bacteria carried by animals and birds can enter the human food chain through the consumption of meat or other animal or bird products (Collignon et al., 2005). The present work was aimed to isolate and identify Salmonella bacteriologically and by molecular method, detection of resistance pattern phenotypically and characterizing antimicrobial resistance genes by using PCR .

\section{Materials and Methods}

\subsection{Samples for surveying Salmonella}

A total of 100 broiler of varying ages (one-day old till 45 day old ) were collected from 19 farm in kafr El-sheikh governorate. From each farm 3-5 live and freshly dead birds were taken for isolation and identification of Salmonella sp.Pooled samples from liver, spleen, gall bladder and cloacal swabs were collected in sterile containers, and were transported directly to the laboratory as soon as possible on the same day of collection to be cultured .

\subsection{Microbiological and molecular analysis (Isolation and identification) \\ 2.2.1-Microbiological methods}

Samples were cultured in Rappaport Vassiliadis Broth at $37{ }^{\circ} \mathrm{C}$ for $18 \mathrm{hrs}$. and then subcultured on XLD agar at $37{ }^{\circ} \mathrm{C}$ for 24-48 hrs. Isolates were identified as Salmonella spp. based on their colony morphology on selective media, biochemical testing (Edwards et al., 1986) and serologically.

\subsection{2-Antimicrobial susceptibility testing}

The antimicrobial sensitivity phenotypes of Salmonella spp. were determined using the Kirby-Bauer disk diffusion method according to the standards and interpretive criteria described by the Clinical and Laboratory Standards Institute (Clinical and Laboratory Standards Institute, 2002).The following antibiotics(Oxiod) were used: amoxicillin-clavulanic acid (AMC), 20/10 $\mu \mathrm{g}$, Ampicillin (AMP), $10 \mu \mathrm{g}$, Cefotaxime (CTX), $30 \mu \mathrm{g}$, Ceftriaxone (CRO), 30 $\mathrm{g}$, Ciprofloxacin (CIP), $5 \mu \mathrm{g}$, Gentamicin (GEN), $10 \mu \mathrm{g}$, Streptomycin (STR), $10 \mu \mathrm{g}$; primers and $1 \mathrm{U}$ of AmpliTaq Gold DNA Polymerase (Applied Biosystems, Roche, NJ, USA). Distilled water was added to bring the final volume to $50 \mu \mathrm{L}$.

\subsubsection{2-Screening for class 1 and class 2 integrons}

The class 1 integron primers, 5'-CS and $3^{\prime}-\mathrm{CS}$, which amplify the region between the $5^{\prime}-\mathrm{CS}$ and $3^{\prime}-\mathrm{CS}$ of class 1 integrons, were used as previously described (Table 1) (Ahmed et al., 2007). For detection of class 2 integrons, PCR was performed with the primer pair hep 74 and hep 51 , which are specific to the conserved regions of class 2 integrons (Ahmed et al.,2007). The reaction products were subjected to electrophoresis in a $1.0 \%$ agarose gel, stained with ethidium bromide and visualized under ultraviolet light.

\subsubsection{3-Screening for antimicrobial resistance genes}

The Salmonella isolates were tested for each of bla resistance genes and qnr genes( TEM, SHV, CTXM, OXA and CMY $\beta$-lactamase-encoding genes),( genes qnr-A, qnr-B , qnr-S ) by PCR using universal primers as described previously (Table 1) (Ahmed et al., 2007).

\section{Results}

The results are summarized in tables (1- 5). From table(5) it is clear that 10 isolates are belonging to Salmonella spp. positive samples $(10 \%)$ and farms $(36.8 \%)$.Ten isolates were confirmed to be Salmonella by Multiplex PCR by using primers specific for genus Salmonella, OMPCF and OMPCR, (with a target PCR amplicon size of 204 bp). By using other pairs of primers specific for the most common Salmonella serovars including enteritidis (target size 304 bp) and typhimurium (target size $401 \mathrm{bp}$ ), the result revealed that 4 isolates belonged to Salmonella enteritidis $(40 \%), 4$ isolates un-typable (40\%) and 2 isolates (20\%) Salmonella typhimurium(Fig.1).

Identified Salmonella isolates were subjected to antibiotic sensitivity test. The results are presented in tables 3 and 4.Testing for antimicrobial susceptibility using disk diffusion method revealed that ten isolates with multidrug resistance phenotypes (Table 5). The most commonly observed resistance phenotypes were recorded against ampicillin, ceftriaxone, ceftazidime, cefotaxime , nalidixic Results in table (2)showed the incidence of both the acid, norfloxacin, enrofloxacin and ciprofloxacin. 
Furthermore, eight isolates showed resistance to multiple extended-spectrum $\beta$-lactam antibiotics such as cefotaxime,ceftazidime, ceftriaxone.(Table 5).

PCR identified CTX-M, a narrowspectrum $\beta$-lactamase gene, which confers resistance to penicillins and firstgeneration cephalosporins, in three MDR Salmonella isolates, (Table 5), CTX-M was identified in one isolate of $S$. enterica serovar Enteritidis, two isolates of other Salmonella spp.(Table 2).

These isolates were resistant to multiple extended-spectrum $\beta$-lactams such as cefotaxime, ceftazidime and ceftriaxone, (Table 5). Also, the extended-spectrum $\beta$-lactamaseencoding genes, blaTEM-1w is identified in one isolate of $S$. enterica serovar typhimurium, one isolate of $S$. enterica serovar enteriditis, two isolates of other Salmonella serovar (Table 5).

These four isolates were resistant to multiple extendedspectrum $\beta$-lactams such as cefotaxime, ceftazidime and ceftriaxone, (Table 5) none of the tested Salmonella isolates were positive for OXA, SHV-12 and CMY-2 $\beta$ lactamase encoding genes (Table 5).

Multiplex PCR-screening and DNA sequencing identified the plasmid-mediated quinolone resistance genes, qnrS , qnrB and qnrA in four isolates of $S$. enterica serovar enteritidis ,typhimurium and other Salmonella (Table 5). In addition, most isolates that were found to harbor quinolone resistance genes were also shown to be resistant to multiple quinolones such as nalidixic acid, ciprofloxacin , norfloxacin and enrofloxacin (Table 5).

\section{Discussion}

Antimicrobial agents have been widely used in poultry to treat infections caused by a variety of bacterial pathogens. However, this widespread use of large quantities of antimicrobials in poultry in some countries, including Egypt, often without professional consultation or supervision, is problematic.

In this study, $100 \%$ of the tested isolates showed multidrug resistance phenotypes, mainly against ampicillin, and its derivatives. Most of theseantimicrobial agents are regularly used in treatment of poultry diseases in Egypt. Similar resistance phenotypes have been detected and isolated from diseased chickens (Yanget et al., 2004 ;Johnson et al., 2005 ;Kimet et al., 2007;Randall et al., 2011 and Obeng et al., 2012).In this study, microbiological examination confirmed that all isolates were of the genus Salmonella.Also, in this study, PCR examination confirmed that all Salmonella isolates were of the genus Salmonella. Further multiplex PCR analysis identified 2 isolates as $S$. enterica serovar Enteriditis and 4 as $S$. enterica serovar Typhimurium.

Antimicrobial susceptibility testing showed that Salmonella isolates displayed multidrug resistance phenotypes, particularly against AMP, CRO, CAZ, and CTX (Table 5). Most of these antimicrobial agents are regularly used in poultry farming (Singer and Hofacre 2006). Similar multidrug-resistance phenotypes of Salmonella isolated from poultry have been reported worldwide (Ahmed et al., 2009).

Interestingly, in this study, many isolates of both $S$. enterica serovar enteritidis and $S$. enterica serovar typhimurium showed resistant phenotypes to the extendedspectrum $\beta$-lactam antibiotics such as CTX, CRO and CAZ (Table 5)

These multidrug resistant phenotypes of Salmonella are of great clinical significance because $\beta$-Lactamases and quinolones and third-generation cephalosporins are considered frontline therapeutic drugs for treatment of typhoidal and other Salmonella infections in hospitals (Bradford , 2001; Hohmann , 2001). The ability of bacteria to acquire and disseminate exogenous genes via mobile genetic elements such as plasmids and transposons has been a major factor in the development of multiple drug resistance over the last 50 years.

The increasing incidence of antimicrobial resistance in bacteria has led to great interest in the genetics and mechanisms of resistance evolved by these bacteria to overcome the effects of antimicrobial agents. A substantial proportion of the resistance genes are present on mobile genetic elements, called integrons, which are integrated into the bacterial DNA .Integrons are capable of capturing individual gene cassettes, which mostly encode antibiotic resistance, by a site-specific recombination system. Hence, integrons play a crucial role in the spread of antibiotic resistance genes in bacteria (Mazel, 2006). Class 1and class 2 integrons are widespread among multi-resistant Gramnegative bacteria (Mazel, 2006). In this study, not class 1 nor class 2 integrons can be identified in $S$. enterica serovars (enteritidis ,typhimurium and non-typable )

$\beta$-lactams belong to a family of antibiotics, the members of which have a $\beta$-lactam ring. Penicillins, cephalosporins, clavams (or oxapenams), cephamycins and carbapenems are members of this family.In Gram-negative bacteria, resistance to $\beta$-lactam antibiotics is primarily mediated by $\beta$-lactamases, which hydrolyze the $\beta$-lactam ring and thus inactivate the antibiotic (Bradford , 2001). Penicillin derivatives ( $\beta$-lactams) are broad spectrum antibacterial agents widely used in human and veterinary medicine. Resistance to $\beta$-lactams in Gram-negative bacteria is primarily mediated by $\beta$-lactamases. In this study, $\beta$ lactamase-encoding genes were detected in ( $60 \%$ ) of isolates.

Many different $\beta$-lactamases have been described, but TEM-, SHV-, OXA-, CMY- and CTX-M- $\beta$-lactamases are the most predominant in Gram-negative bacteria (Livermore and Woodford, 2006). Here, not all groups of $\beta$-lactamases were identified, but only bla $\mathrm{TEM}_{\mathrm{TEM}}$ and bla $\mathrm{CTX}_{\mathrm{CT}}$ were only identified (Table 5). bla $\mathrm{T}_{\mathrm{TEM}}$ was detected in $32.4 \%$ of strains isolated from chickens in Korea (Kim et al., 2007), and also from strains isolated in Spain (Mora et al., 2012). Furthermore, bla $\mathrm{TEM}_{\mathrm{TEM}}$ and bla $\mathrm{C}_{\mathrm{CTX}-\mathrm{M}}$ were reported in strains isolated from broiler chickens and turkeys in the United Kingdom (Randall et al., 2011), while bla ${ }_{\text {TEM }}$ was identified in strains isolated from poultry in Australia (Obeng et al., 2012). 
Table(1): Primers used for PCR and DNA-sequencing

\begin{tabular}{|c|c|c|c|c|}
\hline Primer & Sequence(5'to3') & Amplicon size & Target & Reference \\
\hline \multicolumn{5}{|c|}{ Salmonella serotyping } \\
\hline OMPCF & ATCGCTGACTTATGCAATCG & 204(bp) & Salmonella & Alvarez et al.(2004) \\
\hline OMPCR & CGGGTTGCGTTATAGGTCTG & & & \\
\hline ENTF & TGTGTTTTATCTGATGCAAGAGG & 304 & Enteritidis & Alvarez et al.(2004) \\
\hline ENTR & TGAACTACGTTCGTTCTTCTGG & & & \\
\hline TYPHF & TTGTTCACTTTTTACCCCTGAA & 401 & Typhimurium & Alvarez et al.(2004) \\
\hline TYPHR & CCCTGACAGCCGTTAGATATT & & & \\
\hline \multicolumn{5}{|c|}{ Integrons } \\
\hline $5^{\prime}-\mathrm{CS}$ & GGCATCCAAGCAGCAAG & Variable & Class 1 integron & Ahmed et al.(2007) \\
\hline 3'-CS & AAGCAGACTTGACCTGA & & & \\
\hline hep 74 & $\begin{array}{c}\text { CGGGATCCCGGACGGCATGCACGA } \\
\text { TTTGTA }\end{array}$ & Variable & Class 2 integron & Ahmed et al.(2007) \\
\hline hep 51 & GATGCCATCGCAAGTACGAG & & & \\
\hline \multicolumn{5}{|c|}{ B-lactamases } \\
\hline TEM-F & ATAAAATTCTTGAAGACGAAA & 1080 & $b l a_{\mathrm{TEM}}$ & Ahmed et al.(2007) \\
\hline TEM-R & GACAGTTACCAATGCTTAATC & & & \\
\hline SHV-F & TTATCTCCCTGTTAGCCACC & 795 & $b l a_{\mathrm{SHV}}$ & Ahmed et al.(2007) \\
\hline SHV-R & GATTTGCTGATTTCGCTCGG & & & \\
\hline OXA-F & TCAACTTTCAAGATCGCA & 591 & $b l a_{\mathrm{OXA}}$ & Ahmed et al.(2007) \\
\hline OXA-R & GTGTGTTTAGAATGGTGA & & & \\
\hline CTX-M-F & CGCTTTGCGATGTGCAG & 550 & $b l a_{\text {СТХ-М }}$ & Ahmed et al.(2007) \\
\hline CTX-M-R & ACCGCGATATCGTTGGT & & & \\
\hline CMY-F & GACAGCCTCTTTCTCCACA & 1007 & $b l a_{\mathrm{CMY}}$ & Ahmed et al.(2007) \\
\hline CMY-R & TGGAACGAAGGCTACGTA & & & \\
\hline \multicolumn{5}{|c|}{ Plasmid-mediated quinolone resistance } \\
\hline qnrA-F & ATTTCTCACGCCAGGATTTG & 516 & $q n r \mathrm{~A}$ & Robicsek et al. (2006c) \\
\hline qnrA-R & GATCGGCAAAGGTTAGGTCA & & & \\
\hline qnrB-F & GATCGTGAAAGCCAGAAAGG & 469 & $q n r \mathrm{~B}$ & Robicsek et al. (2006c) \\
\hline qnrB-R & ACGATGCCTGGTAGTTGTCC & & & \\
\hline qnrS-F & ACGACATTCGTCAACTGCAA & 417 & $q n r \mathrm{~S}$ & Robicsek et al. (2006c) \\
\hline qnrS-R & TAAATTGGCACCCTGTAGGC & & & \\
\hline
\end{tabular}


Table (2).Incidence of infection in different farms and samples.

\begin{tabular}{|c|c|c|c|c|c|c|}
\hline Examined farm & + sample & Tot. sample & $\%$ & + farm & total & $\%$ \\
\hline Kafr el-sheikh & 2 & 15 & 13.3 & 1 & 4 & 25.0 \\
\hline Sedi salim & 2 & 23 & 8.7 & 2 & 5 & 40.0 \\
\hline Desouke & 2 & 17 & 11.8 & 1 & 3 & 33.3 \\
\hline Mahalet el kasab & 1 & 10 & 10 & 1 & 2 & 50.0 \\
\hline Sedi ghazy & 2 & 11 & 18.2 & 1 & 2 & 50.0 \\
\hline Sakha & 1 & 24 & 4.2 & 1 & 3 & 33.3 \\
\hline total & 10 & 100 & 10 & 7 & 19 & 36.8 \\
\hline
\end{tabular}

Table (3). The result of different antibiotics against 10 isolates of Salmonella sp.

\begin{tabular}{|c|c|c|c|c|c|c|c|c|c|c|}
\hline \multirow{2}{*}{ Used antibiotic } & \multicolumn{10}{|c|}{ Isolate no. } \\
\hline & 1 & 2 & 3 & 4 & 5 & 6 & 7 & 8 & 9 & 10 \\
\hline Spectinomycin (SPX) & $\mathbf{S}$ & $\mathbf{S}$ & $\mathbf{S}$ & $\mathbf{S}$ & $\mathbf{S}$ & $\mathbf{S}$ & $\mathbf{S}$ & $\mathbf{S}$ & $\mathbf{S}$ & $\mathbf{S}$ \\
\hline Tetracycline (TET) & $\mathbf{S}$ & $\mathbf{S}$ & $\mathbf{S}$ & $\mathbf{S}$ & $\mathbf{S}$ & $\mathbf{S}$ & $\mathbf{S}$ & $\mathbf{S}$ & $\mathbf{S}$ & $\mathbf{S}$ \\
\hline Enrofloxacin (ENR) & $\mathbf{S}$ & $\mathbf{R}$ & $\mathbf{S}$ & $\mathbf{R}$ & $\mathbf{R}$ & $\mathbf{S}$ & $\mathbf{R}$ & $\mathbf{S}$ & $\mathbf{R}$ & $\mathbf{R}$ \\
\hline $\begin{array}{c}\text { amoxicillin-clavulanic acid } \\
\text { (AMC) }\end{array}$ & $\mathbf{S}$ & $\mathbf{S}$ & $\mathrm{R}$ & $\mathbf{S}$ & $\mathbf{S}$ & $\mathbf{S}$ & $\mathbf{S}$ & $\mathrm{R}$ & $\mathbf{S}$ & $\mathbf{S}$ \\
\hline Ampicillin (AMP) & $\mathbf{R}$ & $\mathbf{R}$ & $\mathbf{R}$ & $\mathbf{R}$ & $\mathbf{R}$ & $\mathbf{R}$ & $\mathbf{R}$ & $\mathbf{R}$ & $\mathbf{R}$ & $\mathbf{R}$ \\
\hline $\begin{array}{c}\text { Sulfamethoxazole/trimethoprim } \\
\text { (SXT) }\end{array}$ & $\mathbf{S}$ & $\mathbf{S}$ & $\mathbf{S}$ & $\mathbf{S}$ & $\mathbf{S}$ & $\mathbf{S}$ & $\mathbf{S}$ & $\mathbf{S}$ & $\mathbf{S}$ & $\mathbf{S}$ \\
\hline Ceftriaxone $(\mathrm{CRO})$ & $\mathbf{R}$ & $\mathbf{S}$ & $\mathbf{R}$ & $\mathbf{R}$ & $\mathbf{R}$ & $\mathbf{R}$ & $\mathbf{S}$ & $\mathbf{R}$ & $\mathbf{R}$ & $\mathbf{R}$ \\
\hline Nalidixic acid (NAL) & $\mathbf{S}$ & $\mathrm{R}$ & $\mathbf{S}$ & $\mathbf{R}$ & $\mathbf{R}$ & $\mathbf{S}$ & $\mathrm{R}$ & $\mathbf{S}$ & $\mathbf{R}$ & $\mathbf{R}$ \\
\hline Ceftazidime (CAZ) & $\mathbf{R}$ & $\mathbf{S}$ & $\mathbf{R}$ & $\mathbf{R}$ & $\mathbf{R}$ & $\mathbf{R}$ & $\mathbf{S}$ & $\mathbf{R}$ & $\mathbf{R}$ & $\mathbf{R}$ \\
\hline Gentamicin (GEN) & $\mathbf{S}$ & $\mathbf{S}$ & $\mathbf{S}$ & $\mathbf{S}$ & $\mathbf{S}$ & $\mathbf{S}$ & $\mathbf{S}$ & $\mathbf{S}$ & $\mathbf{S}$ & $\mathbf{S}$ \\
\hline Norfloxacin (NOR) & $\mathbf{S}$ & $\mathbf{R}$ & $\mathbf{S}$ & $\mathbf{R}$ & $\mathbf{R}$ & $\mathbf{S}$ & $\mathbf{R}$ & $\mathbf{S}$ & $\mathbf{R}$ & $\mathbf{R}$ \\
\hline Cefoperazone/sulbactam (SCF) & $\mathbf{S}$ & $\mathbf{S}$ & $\mathbf{S}$ & $\mathbf{S}$ & $\mathbf{S}$ & $\mathbf{S}$ & $\mathbf{S}$ & $\mathbf{S}$ & $\mathbf{S}$ & $\mathbf{S}$ \\
\hline Cefotaxime (CTX) & $\mathbf{R}$ & $\mathbf{S}$ & $\mathbf{R}$ & $\mathbf{R}$ & $\mathbf{R}$ & $\mathbf{R}$ & $\mathbf{S}$ & $\mathbf{R}$ & $\mathbf{R}$ & $\mathbf{R}$ \\
\hline Ciprofloxacin (CIP) & $\mathbf{S}$ & $\mathbf{R}$ & $\mathbf{S}$ & $\mathbf{R}$ & $\mathbf{R}$ & $\mathbf{S}$ & $\mathbf{R}$ & $\mathbf{S}$ & $\mathbf{R}$ & $\mathbf{R}$ \\
\hline
\end{tabular}

Table (4).Summarized results of antimicrobial sensitivity test

\begin{tabular}{|c|c|c|c|c|}
\hline \multirow{2}{*}{ antimicrobial agent } & \multicolumn{3}{|c|}{ Degree of sensitivity } \\
\cline { 2 - 5 } & \multicolumn{2}{|c|}{ resistant } & \multicolumn{2}{c|}{ sensitive } \\
\cline { 2 - 4 } & no. & \% & no. & \% \\
\hline Spectinomycin (SPX) & 0 & 0 & 10 & 100 \\
\hline Tetracycline (TET) & 0 & 0 & 10 & 100 \\
\hline Enrofloxacin (ENR) & 6 & 60 & 4 & 40 \\
\hline amoxicillin-clavulanic acid (AMC) & 2 & 20 & 8 & 80 \\
\hline Ampicillin (AMP) & 10 & 100 & 0 & zero \\
\hline Sulfamethoxazole/trimethoprim (SXT) & 0 & 0 & 10 & 100 \\
\hline Ceftriaxone (CRO) & 8 & 80 & 2 & 20 \\
\hline Nalidixic acid (NAL) & 6 & 60 & 4 & 40 \\
\hline Ceftazidime (CAZ) & 8 & 80 & 2 & 20 \\
\hline Gentamycin (GEN) & 0 & 0 & 10 & 100 \\
\hline Norfloxacin (NOR) & 6 & 60 & 4 & 40 \\
\hline Cefoperazone/sulbactam (SCF) & 0 & 0 & 10 & 100 \\
\hline Cefotaxime (CTX) & 8 & 80 & 2 & 20 \\
\hline Ciprofloxacin (CIP) & 6 & 60 & 4 & 40 \\
\hline
\end{tabular}


Table(5).Resistance phenotype and prevalence of integrons and resistance genes in Salmonella isolated from diseased broilers

\begin{tabular}{|c|c|c|c|}
\hline No. & Serovar & Resistance phenotypes & Resistance gene \\
\hline 1 & $\begin{array}{l}\text { Salmonella } \\
\text { sp. }\end{array}$ & AMP, CAZ , CRO, CTX & $b l a_{\mathrm{TEM}-1}, b l a_{\mathrm{ctx}}$ \\
\hline 2 & $\begin{array}{c}S . \\
\text { typhimurium }\end{array}$ & AMP, CIP ,ENR,NA,NOR & $q n r_{-\mathrm{B}}$ \\
\hline 3 & S.enteriditis & AMC , AMP, CAZ, CRO, CTX & bla $_{\text {TEM-1 }}$ \\
\hline 4 & S. enteriditis & AMP, CAZ,CIP,CRO,CTX,ENR,NA,NOR & $q n r_{-}$ \\
\hline 5 & $\begin{array}{l}\text { Salmonella } \\
\text { sp. }\end{array}$ & AMP, CAZ,CIP,CRO,CTX,ENR,NA,NOR & $q n r-s$ \\
\hline 6 & $\begin{array}{l}\text { Salmonella } \\
\text { sp. }\end{array}$ & AMP, CAZ, CRO, CTX & $b^{\prime l a} a_{\mathrm{ctx}}$ \\
\hline 7 & $\begin{array}{c}S . \\
\text { typhimurium }\end{array}$ & AMP, CIP ,ENR,NA,NOR & $\begin{array}{c}\boldsymbol{b l a}_{\mathrm{TEM}-1,}, b l a_{\mathrm{ctx}}, \\
q n r-\mathrm{s}\end{array}$ \\
\hline 8 & S. enteriditis & AMC , AMP, CAZ, CRO, CTX & - \\
\hline 9 & S. enteriditis & AMP, CAZ,CIP,CRO,CTX,ENR,NA,NOR & $q n r-\mathrm{B}$ \\
\hline 10 & $\begin{array}{l}\text { Salmonella } \\
\text { sp. }\end{array}$ & AMP, CAZ,CIP,CRO,CTX,ENR,NA,NOR & bla $_{\text {TEM-1 }}$ \\
\hline
\end{tabular}

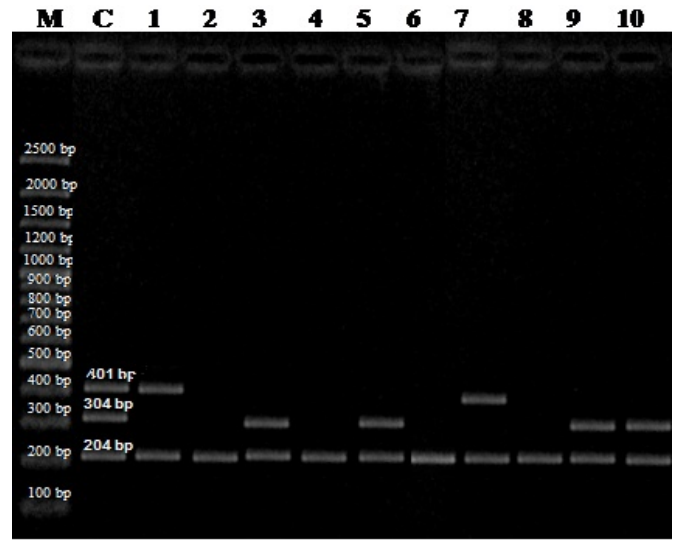

Fig. ( 1 ). Agarose gel electrophoresis for PCR results of serotyping of all isolates for detecting genus Salmonella , Salmonella enteric. M : is 100 base-pair size Marker Ladder, Lane C :204 bp control Positive refers to Salmonella sp.304 bp control positive refers to the species enteritidis, Lane $1 \& 7$ refers to the species typhimurium (401 bp control positive), Lane 3,5,9 \&10 refers to the species enteritidis,Lane 2,4,6\&8 refers to the untyped Salmonellae. It is clear from this figure that All isolates were positive Salmonella sp. at 204 bp positive control ,4 isolates were positive 
In this study, we identified bla ${ }_{\text {TEM }}$ in one isolate of $S$. enterica serovar Enteritidis, one isolate of $S$. enterica serovar Typhimurium and two isolates of other Salmonella spp.(Table 5). bla $\mathrm{TEM}_{\mathrm{T}-1}$ mediates resistance to AMP and $\mathrm{CEF}$, which is clearly reflected in the resistance phenotypes of these isolates (Table 5). TEM $\beta$-lactamase has been previously detected in Salmonella serovars in animals in Japan (Ahmed et al., 2009), Egypt (Ahmed et al., 2009) and

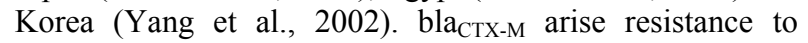
penicillins, extended-spectrum cephalosporins, and monobactams, and the enzymes are inhibited by clavulanate, sulbactam, and tazobactam. Typically, the CTX-M-ases hydrolyze cefotaxime more efficiently than ceftazidime, which is reflected in substantially higher MICs to cefotaxime than to ceftazidime.

bla $_{\text {CTX-M }}$ was detected in one isolate of $S$. enterica serovar Enteritidis and in 2 isolates of other Salmonella serovar (Table 5). bla $\mathrm{a}_{\text {СтХ-M }}$ has previously been identified and reported increasingly in gram-negative rods (Bradford, 2001,Bonnet, 2004, Eckert, et al., 2004,Woodford, et al., 2004 , Hernandez, et al., 2005, Lartigue, et al., 2005, Naas, et al., 2005, Pitout, et al., 2005) and was characterized and isolated in Germany and Italia(Barthelemy et al., 1992, Bauernfeind et al., 1996)

Quinolones are used extensively to combat bacterial poultry pathogens worldwide. In this study, plasmidmediated quinolone resistance genes qnr was identified in $40 \%$ of the tested isolates. qnrB was previously reported in a multidrug-resistant strains in Portugal (Pomba et al., 2009), and in Australia (Platell et al., 2010). In Egypt, qnr has been detected in $6.9 \%$ of Gram-negative bacteria isolated from farms (Ishida et al.,2010). In conclusion, in this study we isolated and identified multidrug-resistant strains ofS. enterica serovar enteritidis and $S$. entericaserovarstyphimurium from diseased broilers in Kafr El-Shiekh.

\section{References}

Aarestrup, F.M.(2005).. Veterinary drug usage and antimicrobial resistance in bacteriaof animal origin. Basic Clin. Pharmacol. Toxicol. 96: 271-281.

Ahmed A.M., Ishida Y. and Shimamoto T. (2009). Molecular characterization of antimicrobial resistance in Salmonella isolated from animals in Japan. J Appl Microbiol 106: 402-9.

Ahmed A.M., Younis E.E.A., Ishida Y. and Shimamoto T. (2009). Genetic basis of multidrug resistance in Salmonella enterica serovars Enteritidis and Typhimurium isolated from diarrheic calves in Egypt. Acta Trop 111: 144-9.

Ahmed A.M., Hussein A.I.A. and Shimamoto T. (2007). Proteus mirabilis clinical isolate harbouring a new variant of Salmonella genomic island 1 containing the multiple antibiotic resistance region. $\mathrm{J}$ Antimicrob Chemother 59: 184-90.

Ahmed A.M., Motoi Y., Sato M., Maruyama A., Watanabe H., Fukumoto Y. and Shimamoto, T. (2007).
Zoo animals asreservoirs of Gram-negative bacteria harboring integrons and antimicrobial resistance genes. Appl Environ Microbiol 73: 6686-90.

Anderson, R. C., and Ziprin ,R. L. (2001). Bacteriology of Salmonella. Pages 247-263 in Foodborne Disease Handbook. Vol. 1. Y. H. Hui, M. D. Pierson, and J. R.Gorham, ed. Marcel Dekker, Inc., New York, NY.

Andrews, H. L., and Baumler,A. J. (2005). Salmonella species. Pages 327-339 in Foodborne Pathogens. P. M. Fratamico, A. K. Bhunia, and J. L. Smith, ed.Caister Academic press, Norfolk, UK.

Barthelemy, M., J. Peduzzi, H. Bernard, C. Tancrede, and Labia,R. (1992). Close amino acid sequence relationship between the new plasmid-mediated extendedspectrum beta-lactamase MEN-1 and chromosomally encoded enzymes of Klebsiella oxytoca. Biochim. Biophys. Acta. 1122:15-22.

Bauernfeind, A., Stemplinger,I., Jungwirth,R., Mangold,P., Amann,S.,Akalin,E., Ang,O. , Bal,C., and Casellas ,J. M.(1996). Characterization of $\beta$-lactamase gene blaPER-2, which encodes an extended-spectrum class A $\beta$ lactamase. Antimicrob. Agents Chemother. 40:616-620.

Bauernfeind, A., Stemplinger,I., Jungwirth,R., Ernst,S., and Casellas. J. M. (1996). Sequences of betalactamase genes encoding CTX-M-1 (MEN-1) and CTXM-2 and relationship of their amino acid sequences with those of other beta-lactamases Antimicrob. Agents Chemother. 40:509-513.

Bennasar, A., G. de Luna, Cabrer,B., and Lalucat,J. (2000). Rapid identification of Salmonella typhimurium, $S$. enteritidis and $S$. Virchow isolates by polymerase chain reaction based fingerprinting methods. Int. Microbiol. 3:3138 .

Bonnet, R. (2004). Growing group of extendedspectrum $\beta$-lactamases: the CTX-M enzymes. Antimicrob. Agents Chemother. 48:1-14.

Bradford, P.A. (2001): Extended-spectrum $\beta$ lactamases in the 21st century: characterization, epidemiology, and detection of this important resistancethreat. Clin Microbiol Rev 14: 933-951.

Brenner, F. W., Villar,R. G., Angulo,F. J., Tauxe,R., and Swaminathan,B.(2000). Salmonella nomenclature. J. Clin. Microbiol. 38:2465-2467.

Castanon, J.I.(2007). History of the use of antibiotic as growth promoters in Europeanpoultry feeds. Poult. Sci. 86:2466-2471.

Collignon, P., Wegener, H.C., Braam, P., Butler, C.D.(2005). The routine use of antibiotics to promote animal growth does little to benefit protein undernutrition in the developing world. Clin. Infect. Dis. 41:1007-1013.

Cooke, F. J., Threlfall,E. J., and Wain,J. (2007). Current trends in the spread and occurrence of human salmonellosis: molecular typing and emerging antibiotic resistance. Pages 1-29 in Salmonella: Molecular Biology and Pathogenesis. Rhen,M.,Maskell,D.,Mastroeni,P., and Threlfall,E. J., ed. Horizon Bioscience,Norfolk, UK.

Eckert, C., Gautier,V., Saladin-Allard,M., Hidri,N., Verdet,C., Ould-Hocine,Z., Barnaud,G., Delisle,F., 
Rossier,A., Lambert,T., Philippon,A., and Arlet,G. (2004). Intoxications. H. P. Riemann, and D. O. Cliver, Dissemination of CTX-M-type beta-lactamases among ed.Academic Press, San Diego, CA,PP.57-136 clinical isolates of Enterobacteriaceae in Paris, France. Antimicrob. AgentsChemother. 48:1249-1255.

Mora, A., López, C., Herrera, A., Viso, S., Mamani,

Edwards, P.R., Ewing,W.H. (1986). Edwards and

Ewing's identification of Enterobacteriaceae (4th ed.), New York, U.S.A: Elseviers Science Publishing Co., Inc.

Euzeby, J. P. (1999). Revised Salmonella nomenclature: Int. J. Syst. Bacteriol. 49(2): 927-930.

Grimont, P. A., Grimont,F., and Bouvet,P. (2000). Taxonomy of the genus Salmonella. In: Salmonella in Domestic Animals. C. Wray, and A. Wray, ed. CAB International, New York, NY,PP1-17

Hanes, D. (2003). NontyphoidSalmonella. In: International Handbook of Foodborne Pathogens. M. D. Miliotis, and J. W. Bier, ed. Marcel Dekker, Inc.,New York, NY,PP 137-149.

Hernandez, J. R., Martinez-Martinez,L., Canton,R. , Coque,T. M. , Pascual, A., and Spanish Group for Nosocomial Infections (GEIH)(2005).Nationwide study of Escherichia coli and Klebsiella pneumoniaproducing extended-spectrum beta-lactamases in Spain. Antimicrob. Agents Chemother. 49:2122-2125.

Hohmann, E. L. (2001). Non-typhoidal salmonellosis. Clin Infect Dis 32: 263-9.

Holt, J. G., Krieg,N. R., Sneath,P. H., Staley,J. T., and Williams,S. T.(1994). Genus Salmonella. In Bergey's Manual of Determinative Bacteriology. W. R. Hensyl, ed. Williams and Wilkins Co., Baltimore, MD, PP.175-289.

Ishida Y., Ahmed A.M., Mahfouz N.B., Kimura T., ElKhodery S.A.,Moawad A.A. and Shimamoto T. (2010). Molecular analysis of antimicrobial resistance in Gramnegative bacteria isolated from fish farms in Egypt. $\mathrm{J}$ Vet Med Sci 72: 727-34.

Johnson, T.J., Siek, K.E., Johnson, S.J. and Nolan, L.K. (2005).DNA sequence and comparative genomics of an avian pathogenic transmissible $\mathrm{R}$ plasmid. Antimicrob. Agents Chemother. 49: 4681-4688.

Kim, T.E., Jeong, Y.W., Cho, S.H., Kim, S.J. and Kwon, H.J. (2007). Chronological study of antibiotic resistances and their relevant genes in Korean avian pathogenic isolates. J. Clin. Microbiol. 45: 3309-3315.

Lartigue, M. F., Poirel,L., Decousser,J. W., and Nordmann,P.(2005). Multidrug resistant Shigella sonnei and Salmonella enterica serotype Typhimurium isolates producing CTX-M beta-lactamases as causes of community-acquired infection in France. Clin. Infect. Dis. 40:1069-1070.

Livermore, D.M. and Woodford, N. (2006). The $\beta$ lactamase threat in Enterobacteriaceae, Pseudomonas and Acinetobacter. Trends Microbiol 14: 413-20.

Martinez, J.L. and Baquero, F.(2002). Interactions among strategies associated withbacterial infection: pathogenicity, epidemicity, and antibiotic resistance. Clin.Microbiol. Rev. 15: 647-679.

Mazel, D. (2006). Integrons: agents of bacterial evolution. Nat Rev Microbiov 4: 608-20.

Molbak, K., Olsen,J. E. and Wegener,H. C.(2006).Salmonella infections. In Foodborne Infection and

R., Dhabi, G., Alonso, M.P., Blanco,M., Blanco, J.E. and

Blanco, J.( 2012): Emerging avian pathogenic strains with

high virulence-gene content and zoonotic potential. Vet. Microbiol. 156,347-352.

Naas, T., Lezzar,A., Bentchouala,C., Smati, F., Scheftel, J. M., Monteil, H. and Nordmann, P. (2005).

Multidrug-resistant Salmonella entericasero type

Senftenberg isolates producing CTX-M beta-lactamases

from Constantine, Algeria. J. Antimicrob.

Chemother. 56:439-440.

Obeng, A.S., Rickard, H., Ndi, O., Sexton, M. and Barton, M.A., (2012). Antibiotic resistance, phylogenetic grouping and virulence potential isolated from the faeces of intensively farmed and free range poultry. Vet. Microbiol. 154:305-315.

Pitout, J. D., Nordmann,P., Laupland,K. B. and Poirel,L. (2005). $\quad$ Emergence of Enterobacteriaceae producing extended-spectrum betalactamases (ESBLs) in the community. J. Antimicrob. Chemother. 56:52-59.

Platell, J.L., Cobbold, R.N., Johnson, J.R. and Trott, D.J. (2010). Clonal group distribution of fluoroquinolones resistant Escherichia coli among humans and companion animals in Australia. J. Antimicrob. Chemother. 65:19361938.

Pomba, C., da Fonseca, J.D., Baptista, B.C., Correia, J.D. and Martinez-Martinez, L.(2009). Detection of the pandemic O25-ST131 human virulent Escherichia coli CTX-M-15-producing clone harboring the qnrB2 and aac(6_)-Ib-cr genes in a dog.Antimicrob. Agents Chemother. 53:327-328.

Randall, L.P., Clouting, C., Horton, R.A., Coldham, N.G., Wu, G., Clifton-Hadley, F.A.,Davies, R.H. and Teale, C.J.(2011). Prevalence of strains carrying extendedspectrum $\beta$-lactamases (CTX-M and TEM-52) from broiler chickens and turkeys in Great Britain between 2006 and 2009. J. Antimicrob. Chemother. 66: 86-95.

Robicsek, A., Strahilevitz, J. andSahm, D.F.(2006c). qnr prevalence in ceftazidime-resistant Enterobacteriaceae isolates from the United States. Antimicrob Agents Chemother 2006c;50:2872-2874.

Singer, R.S. and Hofacre ,C.L. (2006). Potential impacts of antibiotic use in poultry production. Av Dis 50: 161-72.

Woodford, N., Ward,M. E., Kaufmann,M. E., Turton,J., Fagan,E. J., James,D., Johnson,A. P., Pike,R., Warner,M., Cheasty,T., Pearson,A., Harry,S., Leach,J. B., Loughrey,A., Lowes,J. A., Warren,R. E., and Livermore,D. M. (2004)..community and hospital spread of Escherichia coli producing CTX-M extended-spectrum beta-lactamases in the UK. J. Antimicrob. Chemother. 54:735-743.

Yang, S.J., Park, K.Y., Kim, S.H., No, K.M., Besser, T.E., Yoo, H.S., Kim, S.H., Lee, B.K. and Park, Y.H. (2002). Antimicrobial resistance in Salmonella enterica serovars Enteritidis and Typhimurium isolated from 
animals in Korea: comparison of phenotypic and genotypic J.(2004).Characterization of multiple antimicrobial resistant resistance characterization. Vet Microbiol 86: 295-301. isolates from diseased chickens and swine in China. J. Clin.

Yang, H., Chen, S., White, D.G., Zhao, S., Microbiol. 42: 3483-3489.

McDermott, P., Walker, R. and Meng, 